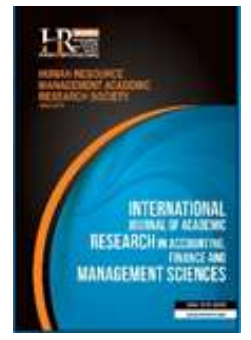

International Journal of Academic Research in Accounting, Finance and Management Sciences

Vol. 9, No.3, July 2019, pp. 353-363

E-ISSN: 2225-8329, P-ISSN: 2308-0337

(C) 2019 HRMARS

www.hrmars.com

To cite this article: Yusof, R. M., Yunus, N. K. Y., Adnan, A. A. Z. (2019). Examining Moderating Effect of Industrial

Relations Climate on Workplace Spirituality and Counterproductive Work Behavior, International Journal of Academic Research in Accounting, Finance and Management Sciences 9 (3): 353-363

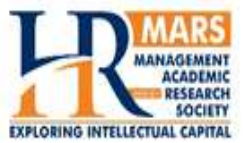

\title{
Examining Moderating Effect of Industrial Relations Climate on Workplace Spirituality and Counterproductive Work Behaviour
}

\author{
Raja Muhamad Yusof ${ }^{1}$, Nek Kamal Yeop Yunus ${ }^{2}$, Ahmad Amri Zainal Adnan ${ }^{3}$ \\ 1,2,3Faculty of Management and Economics, Sultan Idris Education University35900 Tanjung Malim Perak, Malaysia \\ ${ }^{1} E$-mail: a.amri@fpe.upsi.edu.my, ${ }^{2} E$-mail: nkamal@fpe.upsi.edu.my, ${ }^{3} E$-mail: rmyusof@fpe.upsi.edu.my
}

\begin{abstract}
The importance of industrial relations climate has not been given due emphasis on the study of counterproductive work behavior. This variable in facts has great influence to synergize and harmonize the working environment in most of the organizations in today's world. Hence, the purpose of this study is to examine the role of industrial relations climate as moderating variable between the workplace spirituality and counterproductive work behavior. Based on two social theories i.e. Social Control Theory and Social Cognitive Theory and previous research findings, a model has been constructed to demonstrate that positive industrial relations climate could eradicate the intensity of counterproductive work behavior experienced by employees, which in turn could benefit the organizations in doing business. This model would also demonstrate how the integration of industrial relations climate, workplace spirituality and counterproductive work behavior could provide a better understanding in formulating organizational policies especially in engaging employees' positive attributes.

Key words Workplace Spirituality, Counterproductive Word Behavior, Industrial Relations Climate, Moderating, Conceptual, Organizations

\begin{tabular}{|c|c|c|}
\hline Received: & 08 Oct 2019 & (c) The Authors 2019 \\
\hline Revised: & 04 Nov 2019 & Published by Human Resource Management Academic Research Society (www.hrmars.com) \\
\hline $\begin{array}{l}\text { Accepted: } \\
\text { led Online: }\end{array}$ & $\begin{array}{l}08 \text { Nov } 2019 \\
10 \text { Nov } 2019\end{array}$ & $\begin{array}{l}\text { This article is published under the Creative Commons Attribution (CC BY 4.0) license. Anyone may } \\
\text { reproduce, distribute, translate and create derivative works of this article (for both commercial and } \\
\text { non-commercial purposes), subject to full attribution to the original publication and authors. The full } \\
\text { terms of this license may be seen at: http://creativecommons.org/licences/by/4.0/legalcode }\end{array}$ \\
\hline
\end{tabular}
\end{abstract}

\section{Introduction}

Counterproductive work behavior continues to be a world-wide phenomenon and common problem in today's organizations and has been reported to have high rate of occurrences and serious negative impact either economically and socially, which victimizes the organization and its stakeholders (Sulaiman and Bhatti, 2013; Tuclea et al., 2015). Thus, has proliferated and has been one of the significant current discussion that attracted many researchers in studying counterproductive work behaviors since the last decade (e.g. Fox et al., 2012; Rahman et al., 2012; Klotz and Buckley, 2013; Belot and Schroder, 2013; Aleassa, 2014; Brimecombe et al., 2014; Christopher et al., 2015; Deshong et al., 2015; Grijalva and Newman, 2015; Marcus et al., 2016) with the intention to identify its root causes and recognizing the right solutions to eradicate counterproductive behaviors in organizations.

Data from the Association of Certified Fraud Examiners 2014 (ACFE), a study on 100 nations worldwide; revealed that survey participants estimated that the typical organization loses $5 \%$ of revenues each year to fraud. If applied to the 2013 estimated Gross World Product, this translates to a potential projected global fraud loss of nearly $\$ 3.7$ trillion. In addition, the median loss caused by the frauds in the study was $\$ 145,000$ of which $22 \%$ of the cases involved losses of at least $\$ 1$ million. The amount of time 
from when the fraud commenced until it was detected for the fraud cases was 18 months and asset misappropriations are the most common fraud occurring in $85 \%$ of the cases in the study. In a similar statistic (KPMG-UK), fraud barometer for 2013 confirms that identity fraud in 2012 reached to a level high of $f 26.3$ million from $£ 12.3$ million the year before. Forged goods scam rose to $£ 22.9$ million with Ponzi schemes worth $\mathrm{f72}$ million came to courts. The report also presents a similar rising trend for procurement fraud, which grew to $f 21.4$ million in 2012. What's more, the number of cases involving employee fraud increased to 35 in 2012 from 22 as compare to 2011, with values climbing from f12.0 million (2011) to $f$ 25.1 in 2012.

In Malaysian context, a survey (KPMG Malaysia Fraud, Bribery and Corruption Survey 2013); revealed that $83 \%$ of respondent (representing 14 industry segments) felt that fraud is a major problem for Malaysian business and is an inevitable cost of doing business. Of the total reported value of fraud which amounted to RM2.407 million, 45\% were attributed to customers, $32 \%$ were attributed to nonmanagement level employees while $21 \%$ were attributed to service providers.

The National Business Ethics Survey (2013) performed on 6,579 respondents of the USA found that among the forms of counterproductive work behavior that are often reported include abusive behavior, lying to employees, conflicts of interest, violating company policies, and discriminating against employees. Chirasha and Mahapa (2012) posit that 75\% of employees involved in counterproductive work behavior such as theft, fraud, vandalism, sabotage and voluntary absenteeism. It is estimated that $95 \%$ of organizations have experienced theft by their own employees (Case, 2000), causing financial losses between $\$ 50$ and $\$ 200$ billion annually on the US economy (Chirasha and Mahapa, 2012).

Empirical evidences conducted in 32 countries across Asia Pacific, Europe, and North America has reported (Seader, 2012; Bamfield, 2007) that more than one-third of retail shrinkage was attributed to theft committed by employees, and another study conducted by Govoni (1992) reported that American businesses lose over $\$ 200$ billion dollars a year from employee theft alone and Mount et al. (2006) also highlighted that $95 \%$ of organizations claim to have been the target of employee theft. In the Global Retail Theft Barometer survey 2011, revealed that in Asia-Pacific region there were retail shrinkage of $\$ 271$ million with customer theft amounts to $51.2 \%$ (US\$138.75 million) followed by employee theft at $23.3 \%$ (US\$63.14 million), administrative errors $18.9 \%$ and supplier or vendor theft at $6.6 \%$. Malaysia was in ninth place in the highest percentage of retail shrinkage among all 43 countries surveyed and seventh place in the percentage of employee theft among Asia-Pacific countries (The Centre for Retail Research, 2011).

A meta-analysis (Spector et al.; 2014) done on nursing violence literature search of 136 articles (151,347 nurses from 160 samples), found that overall violence exposure rates were $36.4 \%$ for physical violence, $66.9 \%$ for nonphysical violence, $39.7 \%$ for bullying and $25 \%$ for sexual harassment. The rates of violence exposure varied by world region (Anglo, Asia, Europe and Middle East) which the highest rates of physical violence and sexual harassment are in the Anglo region and the highest rate of nonphysical violence and bullying are in the Middle East.

As mentioned earlier, there has been an increased interest in counterproductive work behaviors studies among researchers since its affect decreases works performance and result in organizational losses (Christopher et al., 2015; Chiu et al., 2015; DeShong et al., 2015) However, researchers emphasized on more research to be done (Grijalva and Newman, 2015) and there have been lacking of studies investigating the moderating of counterproductive work behavior (Sprung et al., 2012; Erkuthu and Chafra, 2013; Jensen et al., 2010) and thus has sparked the interest of the researcher to investigate on the moderating roles between the predictors and its relationship with counterproductive work behavior.

\section{Literature Review}

This study is founded on two social theories which underpin the construct of the proposed model.

\subsection{Social Control Theory}

According to the social control theory (Hirschi, 1969), individuals are prevented from engaging in counterproductive work behavior through their bondage with social institutions such as family and religion. He further explained the four types of bonds elements based on (i) attachment to those both within and outside of the family, including friends, teachers, and co-workers; (ii) commitment to activities in which an 
individual has invested time and energy, such as educational or career goals; (iii) involvement in activities that serve to both further bond an individual to others and leave limited time to become involved in counterproductive activities; and finally, (iv) belief in wider social values.

These four elements of social control are thought to interact as to insulate an individual from criminal involvement (Siegel and McCormick, 2006) as well as workplace spirituality which Jurkiewicz et al. (2004) defined as a framework of organizational values. This theory asserts that bonds to social institutions serve to reduce one's propensity for counterproductive behavior. Hence, this theory posits that crime or counterproductive occurs when such bonds are weakened or are not well established. One of the four elements of this social bond is the belief in conventional norms. When this element of the bond is weak, there is a greater likelihood for the individual to become "free" and hence engage in counterproductive behavior. Conversely, when this attachment or bonding is strong it reinforces an employee's purpose or meaningfulness of work which could in turn reduce counterproductive behavior. In nut shell social bonds could be viewed as an agent that would be able to refrain employees from the possibility of conducting counterproductive behavior in the workplace or within organizations.

\subsection{Social Cognitive Theory}

Social Cognitive Theory started as the Social Learning Theory in the 1960 s by Albert Bandura. It developed into the Social Cognitive Theory in 1986 and posits that learning occurs in a social context with a dynamic and reciprocal interaction of the person, environment, and behavior. The unique feature of Social Cognitive Theory is the emphasis on social influence and its emphasis on external and internal social reinforcement. Social Cognitive Theory considers the unique way in which individuals acquire and maintain behavior, while also considering the social environment in which individuals perform the behavior. The theory takes into account a person's past experiences, which factor into whether behavioral action will occur. These past experiences influences reinforcements, expectations, and expectancies, all of which shape whether a person will engage in a specific behavior and the reasons why a person engages in that behavior.

Bandura (2001) identified three basic models of observational learning i.e. (1) a live model, which involves an actual individual demonstrating or acting out behavior (2) a verbal instructional model, which involves descriptions and explanations of behavior (3) a symbolic model, which involves real or fictional characters displaying behaviors in books, films, television programs, or online media. Bandura noted that external, environmental reinforcement was not the only factor to influence learning and behavior. He described intrinsic reinforcement as a form of internal reward, such as pride, satisfaction, and a sense of accomplishment. This emphasis on internal thoughts and cognitions helps connect learning theories to cognitive developmental theories. While many textbooks place social learning theory with behavioral theories, Bandura himself describes his approach as a 'social cognitive theory. This cognitive thought would be able to ascertain employees conduct whether they are prone to counterproductive behavior at the workplace or otherwise. If organizations portray a positive working culture or healthy working environment it will reciprocate to employees' performance and conduct where they will perform positively in general.

\subsection{Counterproductive Work Behavior (CWB)}

Spector (2011) presented a comprehensive review of CWB and defines CWB as an umbrella term that refers to intentional behavior by employees that harms or intends to harm an organization or the people in it, including employees and customers. It can run the gamut from nasty interpersonal behavior (insulting or yelling at someone) to behavior directed toward inanimate objects (sabotage and theft) to purposely doing work incorrectly or withdrawing from an organization via absence or lateness. Hence, within this general construct are two specific types of CWB namely CWB-I that aimed at individuals and CWB-O which targeting the organization.

Spector and Fox (2005) described further on the concept of CWB in the work place that involved five dimensions: (1) abuse against others, (2) sabotage, (3) production deviance, (4) theft, and (5) withdrawal. Abuse against others is a harmful psychological or physical act toward a recipient. An example is making harmful comments about co-workers, such as rumors. Sabotage is behavior where an individual purposefully defaced property of their organization or others. Production deviance is behavior that 
disrupted the productivity of the organization or others, and the behavior is considered a passive form of deviance. Theft is behavior where an individual stole from the organization or other employees. Withdrawal consisted of a number of behaviors where an individual defied organizational requirements and norms. Examples are leaving early from work or taking longer than the allotted break-time requirements.

Numerous studies (e.g. Marcus et al., 2016; Hai and Tziner, 2014) have also attempted to explain and stated that both abuse and production deviances are emotionally charged behaviors in that they are forms of aggression as highlighted by Spector et al., (2006). The last three CWB (i.e., sabotage, theft, and withdrawal) are different from the first two in that the behaviors are not always exclusively emotionally driven. Several studies (e.g. Klotz and Buckley, 2013; Mansur et al., 2015) have revealed that negative work behavior were coded as counterproductive if it was deemed that behavior was voluntary, and likely would result in harm to an organization or an organization's employees. This included behaviors such as workplace aggression, bullying, and abusive supervision, which were conceptualize as specific sub dimensions of the broader, higher-order CWB construct. For example, abusive supervision is defined as "subordinates' perceptions of the extent to which supervisors engage in the sustained display of hostile verbal and nonverbal behaviors, excluding physical contact" (Wei and Si, 2013; Tepper, 2000).

In line with this generic definition, researchers in CWB include a definition that is both broad and unified because, historically, there are many definitions of CWB, as researchers tend to define it in terms of discrete behaviors (e.g., theft, incivility, etc.). It has conclusively been shown that specific CWB are currently conceptualized as belonging to one of several different, yet overlapping definitions that involve the violation of organizational norms (Neuman and Baron, 2005) and include: workplace incivility (DiMarco et al., 2015); corporate psychopath (Boddy, 2013); workplace bullying (Hauge, Skotgrad \& Einarsen, 2009); noncompliant behavior (Puffer, 1987); organizational misbehavior (Vardi and Wiener, 2004); workplace deviance (Robinson and Bennett, 1995); workplace aggression (Baron and Neuman, 1996); antisocial behavior (Giacalone and Greenberg, 1997); organizational retaliation behaviors (Skarlicki and Folger, 1997); and dysfunctional behavior (Griffin et al., 1998).

A review of past literature (Rahman et al., 2012) showed that regardless of the different terms that have been employed, CWB share some common characteristics namely: (1) it reflects any form of behavior that violates customary norms or values either dominant organizational norms, societal norms, or violates both norms, (2) it indicates intentions that could be either voluntary or intentional that will or cause harm to the organization, its members or both; and, (3) it results in negative consequences to the organization, its members or even other people that have direct connection with the organization.

With the above arguments, it was concluded that CWB has no fixed empirical definitions and subjected to interpretation by scholars (Jacobson, 2009). However, for the purpose of this study, the researcher will adhere to the definition of Spector and Fox (2010) that defined CWB as a voluntary behavior that violates significant organizational norms, and in doing so, threatens the well-being of an organization, its members, or both. Behavior such as aggression, theft, sabotage, coming to work late without excuses and illegal drug use are all considered forms of CWB (Spector and Fox, 2010) and these behavior are harmful to the organization by directly affecting its functioning or property, or by hurting employees in a way that will reduce their effectiveness.

\subsection{Workplace Spirituality}

The word spirituality evolved from the Latin word 'spiritus', which means breath - the breath of life (Kumara et al., 2014). There are many definitions of spirituality that vary widely in scientific literature (Kumpikaite, 2009). However Pandey and Gupta (2008), viewing the fundamental conceptualization of spirituality and the definitions given in contemporary literature, defines spirituality as a multidimensional and multilevel phenomenon. Workplace spirituality is commonly described in terms of an employee experiencing a sense of 'wholeness, connectedness at work, and deeper values. In practice, however, the meaning of this construct is less than clear and it is often used interchangeably with the phrases 'spirit at work' or 'spirituality at work' (Komala and Ganesh, 2007).

Spirituality in the workplace differs from the usual concept of spirituality. It is about people who have a common connection, magnetism, and togetherness with each other in their work unit and about the 
organization as a whole (Gupta et al., 2014; Harrington 2004). The concept also involves an employee being perceived as a spiritual entity and finding fulfillment of the spirit and of desire through work.

People often confuse religion and spirituality, thinking that they are the same thing. In truth, the two are quite different. A spiritual person can also be religious, but a religious person is not always spiritual because it is simple to follow a religion but difficult to be spiritual. Religion presents absolute realities in life. Religion forms the basis of the present society in which we live, whereas spirituality (the truth of our soul within) upholds the values in the society. Without spirituality, the physically visible world would not be sustained for long, whereas in the absence of religion, society could survive on its own. Therefore, spirituality is better because it avoids the drawback of religious teaching. Gupta et al., (2014) further emphasised that "spirituality is a path that takes us on an inward journey into the self. With the help of this inward journey, we search deep into our souls via a path that will lead us to God".

The concept of spirituality has been studied in a variety of disciplines. The study of spirituality can be regarded as a prescriptive human science standing at the interface of psychology and theology (Helminiak, 1998). Spirituality is a topic within the psychology of religion (Helminiak, 2006; Pargament, 1999) and is closely related to the five-factor model of personality (MacDonald, 2000; Piedmont, 1999). Spirituality corresponds to the higher stages of consciousness in transpersonal psychology (Walsh and Vaughan, 1980; Wilber, 1993; Wilber, 2006; Wilber et al., 1986).

Many scholars link spirituality meaning to a larger purpose and to a source beyond one-self (Valiūnienè, 2014; Ashar and Maher, 2004). Generally, they point to three principles that all spiritual traditions maintain, which are: (a) a unifying force, or energy, exists in the nature of everything; (b) this universal power lies within each of us; and (c) we are all capable of experiencing this power. Delbecq (1999) referred to this universal energy when he defines spirituality as the individual's lived experience of the transcendent, "whether that be God, the Buddha, the Dao, or the Force" (Leigh-Taylor, 2000). McCormick (1994) spoke of the "beyond," and Conger (1994) alluded to the transcendental quality of spirituality more implicitly when he claimed that spirituality "lifts us beyond ourselves and our narrow self-interests, it is the most humane of forces. It helps us to see our deeper connection to one another and to the world beyond ourselves" (Valiuniene, 2014).

According to Marcic (2000) who reviewed about 100 of books and another 100 journal articles, found that less than $20 \%$ of them mention God or a Higher Power. The journal articles had even less recognition of God, with no more than $10 \%$ acknowledging that God may be part of spirituality (Marcic, 2000). Consequently, some spiritual beliefs and practices are founded in religion and others are unconnected to any religious doctrine in organization (Valiuniene, 2014; Lewis and Geroy, 2000).

Another concept that was defined by Ashmon and Duchon (2000), states that spirituality at work as the recognition that employees have an inner life that nourishes and is nourished by meaningful work that takes place in the context of community. Hence, the spirituality at work consists of the three components that are, i) the inner life ii) meaningful work and iii) sense of community. Ashmon and Duchon also emphasized that spirituality at work is not about religion, although may sometimes express their religious beliefs at work. The spirit is nourished in sacred as well as secular places.

A second consideration relates to the interchangeable use of the concepts workplace spirituality and spirituality (or spirit) at work. Most scholars would refer to workplace spirituality but discuss spirituality in the context of the workplace or environment. While this is by far the most common approach, Kolodinsky et al. (2008), for example, have argued that at least three different perspectives on workplace spirituality are evident from scholarly reports: i) Workplace spirituality as the application of personal spirituality in the workplace, i.e. the transfer of individual spiritual ideals and values to the work setting. ii) Workplace spirituality as organizational spirituality, i.e. the organization's spiritual values (the individual employee's perception of). iii) Workplace spirituality as interactive workplace spirituality, which entails the interaction of the individual employee's personal spiritual values with the spiritual values of the organization.

Hill et al. (2013), observed that the field of spirituality has received increased attention in the organizational sciences, and it is a fast growing area of research and inquiry, with important implications for leadership theory, research, and practice. According to Benefiel et al., (2014) essential to spiritual leadership are the key processes of (1) Creating a transcendent vision of service to others whereby one experiences a sense of calling so that one's life has purpose and meaning and makes a difference and (2) 
Establishing or reinforcing an organizational culture based on the values of altruistic love whereby one has a sense of membership, feels understood and appreciated, and has genuine care, concern, and appreciation for both self and others.

\subsection{Workplace Spirituality and Counterproductive Work Behaviors}

Workplace spirituality has become increasingly prevalent in the United States work environment as a growing number of employees seek value, support, and meaning in their work as well as their lives (Sprung et al., 2012, Gray and Rood, 2000,) within organizations, workplace spirituality may provide benefits for employees and organizational strategy. For example, Milliman et al. (2003) found that workplace spirituality was related to organizational commitment, intentions to quit, intrinsic work satisfaction, and organization-based self-esteem. Furthermore, spiritual employees may perform better due to increased feelings of motivation and meaning in their work (Altaf and Awan, 2011; Garcia-Zamor, 2003). As such, there is evidence suggesting that workplace spirituality plays an important role in the work environment. From the perspectives of Muslim's organization study (Sulaiman and Bhatti, 2013) it has suggested that the workplace spirituality can be one factor that may be utilized to overcome many issues. The vertical and horizontal dimensions of spirituality helps one achieve a sense of direction and purpose in life. It helps one achieve desires and satisfaction at large and may also provide employees with better interaction, communication, build honesty and trust among them.

A number of studies using multiple measures have found workplace spirituality to be positively related to organizational commitment, job satisfaction, productivity, and other measures of performance (Benefiel et al., 2014). In addition, the empirical research on workplace spirituality has demonstrated that measures of spirituality are significantly related to altruism and conscientiousness (Chen and Yang, 2012); self-career management (Chen et al., 2012); reduced inter-role conflict (Hall et al., 2012); reduced frustration (Kolodinsky et al., 2008); organization- based self-esteem (Milliman et al., 2003); involvement (Kolodinsky et al., 2008); retention (Milliman et al., 2003); and ethical behavior (Ming-Chia, 2012). These results are consistent across various countries and cultures, including Brazil, China, India, Iran, Malaysia, Pakistan, Taiwan, and the United States (Benefiel et al., 2014).

Kim and Seidlitz (2002) found that workplace spirituality buffered the adverse effects of stress on emotional and physical adjustment, suggesting that workplace spirituality may serve as a resource in combating negative effects associated with the environment. Applied to the workplace, people who face a stressful situation may react differently depending on their level of spirituality. When faced with difficulties, spirituality may serve as a buffer, lessening the impact of counterproductive work experiences; employees may use spirituality to cope with the work environment through various strategies such as meditation, spiritual contemplation, or prayer (Daniel, 2015; Cash et al., 2000). Additionally, spiritual employees may view potential problems as opportunities for personal growth and reflection rather than a hindrance (Zinnbauer et al., 1999).

\subsection{The Moderating: Industrial Relations Climate}

IRC is viewed as pertains to the norms and attitudes reflecting union-management relationships in an organization (Dastmalchian et al., 1989). It is also being defined as "the degree to which relations between management and employees are seen by participants as mutually IRC-trusting, respectful, and cooperative" (Snape and Redman, 2012). From another perspective, IRC refers to the atmosphere, norms, attitudes and behaviors reflecting and underpinning how workers, unions and managers interact collectively with each other in the workplace, which in turn, affects workplace outcomes (Kersley et al., 2006). Due to its operational functionality, IRC may hold diversified perceptions or attitudes of interactions between 'organizational members', individuals and groups within an organization (Schneider and Reichers 1983).

Snape and Redman (2012) postulated that the climate is a characteristic of a particular workplace, reflecting the history, management style, and industrial relations context, rather than simply the individual psychology of climate survey respondents. According to this view, climate reflects to some degree the shared experience and perceptions of members of the workplace. Hence, the term IRC has commonly been used to describe the quality of labour-management relations in the organization (Konstantina, 2013; Wu and Lee, 2001; Deery et al., 1999). It has been seen as reflecting the perceptions of organizational members 
about the conduct and practice of union-management relations within the organizations (Lee, 2004; Blyton et al., 1987). The IRC of the organization will be affected by important number of factors such as the organization's policies, actions of union's officials, plant-level managers' attitude and other decision-makers in the organizations.

Bose and Mudgal (2013) point out that union and management officials are instrumental in establishing the tone of contract negotiations and the willingness to employ a joint problem-solving approach to grievance resolution. Where management, for example, uses its power to limit the subjects of bargaining and to extend unilateral control over the labour process, it is likely that unions and employees will be less inclined to take a co-operative approach to the resolution of conflict. Alternatively, where unions and employees are integrated into the decision-making process, a climate of goodwill and IRC-trust is more likely to emerge (Pyman et al., 2010; Belman, 1992).

In congruence with the social control theory and social cognitive theory Colquitt et al. (2013) argued that indicators of high-quality social exchange, such as trust and a good relationship between management and employees would be able to moderate the counterproductive work behavior. Accordingly, this study would foresee that industrial relations climate would play a moderating role in the relationship between the personal-related factor i.e. workplace spirituality and environmental-related factors link such as the counterproductive work behavior. There are two reasons for this prediction, as follows: first, a positive industrial relations climate, characterized by high-quality social control, will trigger employees' constructive behaviors through the reciprocity mechanism (Blau, 1964; Deery et al., 1999); second, the industrial relations climate is an important component of employees' shared perception about the employment relationship (Snape and Redman, 2012), and will influence attitude (job performance) and employees' behavior in the organizations (Salancik and Pfeffer, 1978).

\subsection{The Model and Hypotheses}

Based on these two theories, social control theory and social cognitive theory we developed a moderation model which we believe could moderate between the link of workplace spirituality and counterproductive work behavior. Based on previous findings, it is evident that the relationship between the two variables and industrial relations climate has strong influences between them. In this model, we argue that changes in the extent of industrial relations climate in the workplace could lead to changes in the intensities of workplace spirituality which in turn could affect individuals' level of engagement in counterproductive work behavior. To put it indirectly, the model postulates that good environment at workplace such as working in harmony and trust-worthy environments would trigger fewer conflicts in the company and employees would be able to perform or engage to their best potential at the workplace. By increasing the employees' working spirituality at workplace will also in long run benefit the organizations' performance and addition to it would harmonize the working environment.

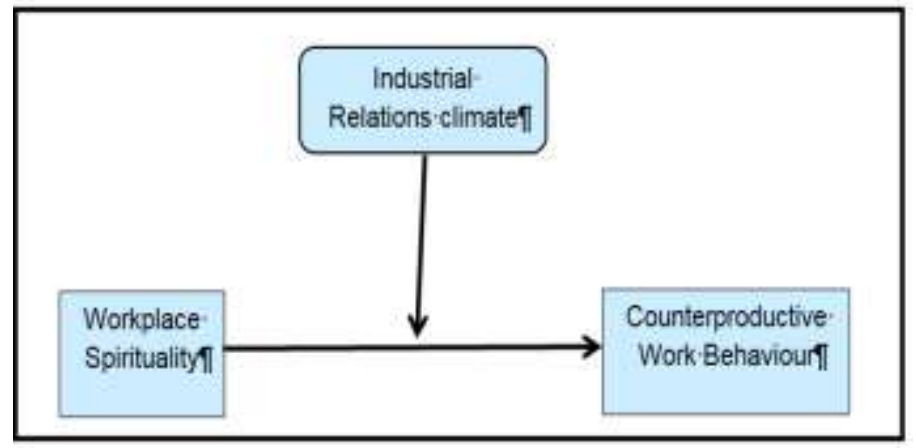

Figure 1. A moderating model of industrial relations climate on the relationship between workplace spirituality and counterproductive work behavior

Hence, this study extends counterproductive work behavior research by examining industrial relations climate as a potential moderator and we foresee that industrial relations climate will ameliorate and further enhance the negative relationship between workplace spirituality and counterproductive work 
behavior. Therefore, the direct relationship between the independent variable and dependent variable of the research will be moderated by the moderating variable.

Thus, it is hypothesized that Industrial Relations Climate will moderate the negative relationship between workplace spirituality and counterproductive work behavior. In other words it simply means that the moderating impact of industrial relations climate on the relationship between workplace spirituality and counterproductive work behavior would strengthen for individual employee when the industrial relations climate is high as compared to when the industrial relations climate is low. Therefore, we formed the following hypotheses:

H1: There is significant and negative relationship between workplace spirituality and counterproductive work behavior.

$\mathrm{H} 2$ : Industrial relations climate will moderate the negative relationship between workplace spirituality and counterproductive work behavior. Specifically, the moderating impact of positive industrial relations climate on the relationship between workplace spirituality and counterproductive work behavior would decrease further for individual with high spirituality as compared to low spirituality.

\section{Conclusions}

There are a lot of scholars still in the dark in finding the right formula to eradicate counterproductive work behavior activities in the organizations although many have suggested various intervening mechanisms. However, there is lack of attention given to industrial relations climate factor as a mechanism through moderating variable which would pacify the intensity of counterproductive work behavior in organizations. In this study we propose and develop a model based on social control theory and social cognitive as to demonstrate that industrial relations climate would be able to become an agent in eliminating counterproductive behavior among employees.

The workplace spirituality factor combining with positive industrial relations climate will be the best deterrence elements in combating negative attitudes, ill-discipline and non-performance issues in organizations. This model would also demonstrates how the integration of the workplace spirituality compounded with industrial relations climate interface and counterproductive work behavior literatures could provide a better understanding of organizations' predicament on employee disciplinary and performance issues in workplace.

\section{References}

1. Aleassa, H. M. (2014). Performance Appraisal Satisfaction and Counterproductive Behaviors: Direct and Moderating Effects. International Journal of Business Administration, 5(1), 76-90.

2. Altaf, A., \& Awan, M. A. (2011). Moderating effect of Workplace Spirituality on the Relationship of Job Overload and Job Satisfaction. Journal of Business Ethics, 104(1), 93-99. https://doi.org/10.1007/s10551-011-0891-0

3. Association of Certified Fraud Examiners at www.acfe.com

4. Bamfield, J. (2007). Global retail theft barometer. Nottingham: Centre for Retail Research.

5. Bandura, A. (2001). Social cognitive theory: An agentic perspective. Annual Review of Psychology, 52, 1-26.

6. Belot, M., \& Schröder, M. (2013). Sloppy Work, Lies and Theft: A Novel Experimental Design to Study Counterproductive Behavior. Journal of Economic Behavior and Organization, 93, 233-238.

7. Bennett, T. (2014). Do Union-Management Learning Partnerships Reduce Workplace Conflict? Employee Relations, 36(1), 17-32.

8. Benefiel, M., Fry, L. W., \& Geigle, D. (2014). Spirituality and religion in the workplace: History, theory, and research. Psychology of Religion and Spirituality, 6(3), 175-187. 
9. Boddy, C. R. (2013). Corporate Psychopaths, Conflict, Employee Affective Well-Being and Counterproductive Work Behavior. Journal of Business Ethics, 1-15.

10. Brimecombe, M., Magnusen, M. J., \& Bunds, K. (2014). Navigating The Storm: A Counterproductive Work Behavior And Leadership Case Study In A Division I FBS School. Sport Management Review, 17(2), 219-237.

11. Chen, M., \& Sheng. (2013). Workplace Spirituality and Earnings Management Motivations. International Journal of Business \& Information, 8(2), 267-298.

12. Chirasha, V., \& Mahapa, M. (2012). An Analysis of the Causes and Impact of Deviant Behavior in the Workplace. The Case of Secretaries in State Universities. Emerging Trends in Economics and Management Sciences (JETEMS), 3(5), 415-421

13. Christopher, A., Fatimah, O., Fatimahwati, H., \& Sarahwaheeda, H. (2015). The Mediating Role of Organizational-Based Self-Esteem in Perceived Organizational Support and Counterproductive Work Behavior Relationship. International Journal of Business and Management, 10(9), 99-109.

14. Chiu, S.-F., Yeh, S.-P., \& Huang, T. C. (2015). Role Stressors and Employee Deviance: The Moderating Effect of Social Support. Personnel Review, 44(2), 308-324.

15. Deshong, H. L., Grant, D. M., \& Mullins-Sweatt, S. N. (2015). Comparing Models Of Counterproductive Workplace Behaviors: The Five-Factor Model And The Dark Triad. Personality and Individual Differences, 74, 55-60.

16. Di Marco, D., Hoel, H., Arenas, A., \& Munduate, L. (2015). Workplace Incivility as Modern Sexual Prejudice. Journal of Interpersonal Violence.

17. Erkutlu, H., \& Chafra, J. (2013). Effects of trust and Psychological Contract Violation on Authentic Leadership and Organizational Deviance. Management Research Review, 36(9), 828848.

18. Fox, S., Spector, P. E., Goh, A., Bruursema, K., \& Kessler, S. R. (2012). The Deviant Citizen: Measuring Potential Positive Relations between Counterproductive Work Behavior and Organizational Citizenship Behavior. Journal of Occupational and Organizational Psychology, 85(1), 199-220.

19. Garcia-Zamor, J.C. 2003. 'Workplace spirituality and organizational performance'. Public Administration Review, 63(3): 355-363.

20. Giacalone, R. A., \& Greenberg, J. (1997). Antisocial behavior in organizations. Newbury Park, CA: Sage.

21. Govoni, S. J. (1992). To catch a thief. CFO. February, 24-32.

22. Griffin, R. W., O'Leary-Kelly, A., \& Collins, J. (1998). Dysfunctional work behaviors in organizations. In C. L. Cooper \& D. M. Rousseau (Eds.), Trends in organizational behavior, Vol. 5, pp. 65-82. New York, Wiley.

23. Grijalva, E., \& Newman, D. A. (2015). Narcissism And Counterproductive Work Behavior (CWB): Meta-Analysis and Consideration of Collectivist Culture, Big Five Personality, and Narcissism's Facet Structure. Applied Psychology, 64(1), 93-126.

24. Gupta, M., Kumar, V., \& Singh, M. (2014). Creating Satisfied Employees Through Workplace Spirituality: A Study Of The Private Insurance Sector In Punjab (India). Journal of Business Ethics, 122(1), 79-88.

25. Hai C.L., \& Tziner, A. (2014). Relationships between Counterproductive Work Behavior, Perceived Justice and Climate, Occupational Status and Leader-Member Exchange. Journal of Work and Organizational Psychology, 30(1), 1-12.

26. Hauge, L. J., Skogstad, A., \& Einarsen, S. (2009). Individual and Situational Predictors of Workplace Bullying: Why Do Perpetrators Engage In The Bullying of Others? Work \& Stress, 23(4), 349-358. 
27. Jacobson, K. J. L. (2009). Contextual and Individual Predictors of Counterproductive Work Behaviors. Phd Thesis. Arizona State University.

28. Jensen, J. M., Opland, R. A., \& Ryan, A. M. (2010). Psychological Contracts and Counterproductive Work Behaviors: Employee Responses to Transactional and Relational Breach. Journal of Business and Psychology, 25, 555-568.

29. Jurkiewicz, C., Giacalone, R., \& Knouse, S. (2004). Transforming personal experience into a pedagogical tool: Ethical complaints. Journal of Business Ethics, 53(3), 283-295.

30. Klotz, A. C., \& Buckley, M. R. (2013). A Historical Perspective of Counterproductive Work Behavior Targeting the Organization. Journal of Management History, 19(1), 114-132.

31. Kolodinsky, R. W., Giacalone, R. a., \& Jurkiewicz, C. L. (2008). Workplace values and outcomes: Exploring personal, organizational, and interactive workplace spirituality. Journal of Business Ethics, 81(2), 465-480. http://doi.org/10.1007/s10551-007-9507-0.

32. Konstantina K. (2013). Effective Joint Consultative Committees: An exploration of the role of Trust and Justice, Durham Thesis, Durham University.

33. Komala, K. and Ganesh, L. (2007), "Individual spirituality at work and its relationship with job satisfaction and burnout: an exploratory study among healthcare professionals", The Business Review, Vol. 7 No. 1, pp. 124-9.

34. KPMG-UK at http://home.kpmg.com.uk/

35. KPMG-Malaysia at http://home.kpmg.com.my/

36. Kumara V., Jain A., Rahman Z. and Jain A. (2014). Marketing Through Spirituality: A case of Patanjali Yogpeeth, Procedia-Social and Behavioral Science 133, 481-490.

37. Kumpikaitè, V. (2009). Attitudes of spirituality: pilot study from Lithuania. The Business Review, 13(1), 271-277.

38. Manzoor, S. R., Khattak, I. A., \& Hassan, S. (2015). Psychological Capital and Counterproductive Work Behavior with Intrusion of Employee Performance: Study from Kp, Pakistan. City University Research Journal, 05(02), 372-383.

39. Marcus, B., Taylor, O. A., Hastings, S. E., Sturm, A., \& Weigelt, O. (2016). The Structure of Counterproductive Work Behavior: A Review, a Structural Meta-Analysis, and a Primary Study. Journal of Management, 42(1), 203-233.

40. Milliman, J., Czaplewski, A. J., \& Ferguson, J. (2003). Workplace spirituality and employee work attitudes an exploratory empirical assessment. Journal of Organizational Change Management, 16(4), 426-447. https://doi.org/10.1108/09534810310484172.

41. Mount, M., Ilies, R., \& Johnson, E. (2006). Relationship of Personality Traits and Counterproductive Work Behaviors: The Mediating Effects of Job Satisfaction. Personnel Pschology, 59(3), 591-622.

42. Neuman, J.H., \& Baron, R.A. (2005). Aggression in the workplace: A social-psychological perspective. In S. Fox \& P.E. Spector (Eds.), Counterproductive work behavior: Investigations of actors and targets (pp. 13-40). Washington, DC: American Psychological Association.

43. Pandey, A., \& Gupta, R.K. (2008). Spirituality in Management: A Review of Contemporary and Traditional Thoughts and Agenda for Research. Global Business Review, 9(1), 65-83.

44. Puffer, S.M. (1987). Prosocial behavior, noncompliant behavior, and work performance among commission salespeople. Journal of Applied Psychology, 72, 615-621

45. Pyman, A., Holland, P., Teicher, J., \& Cooper, B. K. (2010). Industrial Relations Climate, Employee Voice and Managerial Attitudes to Unions: An Australian Study. British Journal of Industrial Relations, 48(2), 460-480.

46. Rahman, R., Alwi, S., \& Aizzat, N. (2012). Effects of Job Characteristics on Counterproductive Work Behavior among Production Employees: Malaysian Experience. International Journal of Business and Development Studies, 4(1), 123-145. 
47. Robinson, S.L., \& Bennett, R. J. (1995). A typology of deviant workplace behaviors: A multidimensonal scaling study. Academy of Management Journal, 38(2), 555-564.

48. Salancik, G. R., \& Pfeffer, J. (1978). A social information processing approach to job attitudes and task design. Administrative Science Quarterly, 23(2), 224-253.

49. Seader, J. (2012). Examining The Relationship between Emotional Intelligence and Counterproductive Work Behaviors with a Food Service, Phd thesis, Capella University.

50. Siegel, L., \& McCormick, C. (2006). Criminology in Canada: Theories, patterns, and typologies (3rd ed.). Australia: Thomson Nelson.

51. Skarlicki, D. P., \& Folger, R. (1997). Retaliation in the workplace: The roles of distributive, procedural, and interactional justice. Journal of Applied Psychology, 82, 434-443.

52. Spector, P.E. (1987). Method variance as an artifact in self-reported affect and perceptions at work: Myth or significant problem? Journal of Applied Psychology, 72, 438-443.

53. Spector, P. E., Zhou, Z. E., \& Che, X. X. (2014). Nurse Exposure to Physical and Nonphysical Violence, Bullying, And Sexual Harassment: A Quantitative Review. International Journal of Nursing Studies, 51(1), 72-84.

54. Spector, P. E., \& Fox, S. (2002). An Emotion-Centered Model of Voluntary Work Behavior Some Parallels between Counterproductive Work Behavior and Organizational Citizenship Behavior. Human Resource Management Review, 12, 269-292.

55. Spector, P. E., Fox, S., \& Domagalski, T. (2005). Emotions, Violence, and Counterproductive Work Behavior. In Perspectives on Workplace Violence (pp. 29-46).

56. Sprung, J. M., Sliter, M. T., \& Jex, S. M. (2012). Spirituality as a Moderator of the Relationship between Workplace Aggression and Employee Outcomes. Personality and Individual Differences, 53(7), 930-934.

57. Sulaiman, M., \& Bhatti, O. K. (2013). Workplace Deviance and Spirituality in Muslim Organizations. Asian Social Science, 9(10), 237-246.

58. Tepper, B. J., Carr, J. C., Breaux, D. M., Geider, S., Hu, C., \& Hua, W. (2009). Abusive supervision, intentions to quit, and employees' workplace deviance: A power/dependence analysis. Organizational Behavior and Human Decision Processes, 109: 156-167

59. Țuclea, C.-E., Vrânceanu, D.-M., \& Filip, A. (2015). Dimensions of Deviant Workplace Behavior in Small and Medium-Sized Enterprises. Review of International Comparative Management, 16(1), 23-38.

60. Vardi, Y., \& Wiener, Y. (1996). Misbehavior in organizations: A motivational framework. Organization Science, 7, 151-165.

61. Wei, F., \& Si, S. (2013). Tit for tat? Abusive supervision and counterproductive work behaviors: The moderating effects of locus of control and perceived mobility. Asia Pacific Journal of Management, 30(1), 281-296. 